\title{
A Prospective, Population-Based Study of the Role of Visual Impairment in Motor Vehicle Crashes among Older Drivers: The SEE Study
}

\author{
Gary S. Rubin, ${ }^{1}$ Edmond S. W. $\mathrm{Ng}^{2}{ }^{2}$ Karen Bandeen-Roche, ${ }^{3}$ Penelope M. Keyl, ${ }^{4}$ \\ Ellen E. Freeman, ${ }^{5}$ Sheila K. West, ${ }^{5}$ and the SEE Project Team ${ }^{6}$
}

Purpose. To determine the role of vision and visual attention factors in automobile crash involvement.

Methods. Drivers aged 65 to 84 years were identified during the baseline interview (1993-1995) of the Salisbury Eye Evaluation (SEE) Study. Crash involvement through December 1997 was determined from Maryland State motor vehicle records. Vision tests at baseline included distance acuity at normal and low luminance, contrast sensitivity, glare sensitivity, stereoacuity, and visual fields. Visual attention was evaluated with the Useful Field of View Test (UFOV; Visual Awareness, Chicago, IL). Survival analysis was used to determine the relative risk of a crash as a function of demographic variables, miles driven, vision, and visual attention.

Results. One hundred twenty (6.7\%) of the 1801 drivers were involved in a crash during the observation interval. Glare sensitivity and binocular field loss were significant predictors of crash involvement $(P<0.05)$. For those with moderate or better vision $(<3$ letters for glare sensitivity and $<20$ points missed for binocular visual fields) increased glare sensitivity or reduced visual fields were, paradoxically, associated with a reduction in crash risk, whereas for those with poorer levels of vision, increased glare sensitivity or reduced visual fields were associated with increased crash risk. Worse UFOV score was associated with increased crash risk.

Conclusions. Glare sensitivity, visual field loss, and UFOV were significant predictors of crash involvement. Acuity, contrast sensitivity, and stereoacuity were not associated with crashes. These results suggest that current vision screening for drivers' licensure, based primarily on visual acuity, may miss important aspects of visual impairment. (Invest Ophthalmol Vis Sci. 2007;48:1483-1491) DOI:10.1167/iovs.06-0474

From the ${ }^{1}$ Institute of Ophthalmology, University College London, United Kingdom; the ${ }^{2}$ Medical Statistics Unit, London School of Hygiene and Tropical Medicine, London, United Kingdom; the ${ }^{3}$ Department of Biostatistics, Bloomberg School of Public Health, Johns Hopkins University, Baltimore, Maryland; ${ }^{4}$ Keyl Associates, East Sandwich, Massachusetts; and the ${ }^{5}$ Dana Center for Preventive Ophthalmology, Department of Ophthalmology, Johns Hopkins University, Baltimore, Maryland.

${ }^{6}$ Group members are listed in the Appendix.

Supported by National Institute on Aging Grants AG16294 and AG14684. SKW is a Research to Prevent Blindness senior scientific investigator.

Submitted for publication April 26, 2006; revised September 18, November 16, and December 15, 2006; accepted February 15, 2007.

Disclosure: G.S. Rubin, None; E.S.W. Ng, None; K. BandeenRoche, None; P.M. Keyl, None; E.E. Freeman, None; S.K. West, None

The publication costs of this article were defrayed in part by page charge payment. This article must therefore be marked "advertisement" in accordance with 18 U.S.C. $\$ 1734$ solely to indicate this fact.

Corresponding author: Gary S. Rubin, UCL Institute of Ophthalmology, 11-43 Bath Street, London EC1V 9EL, UK; g.rubin@ucl.ac.uk.
$\mathrm{D}$ espite the fact that older drivers are involved in fewer motor vehicle crashes than any other age group, they have more crashes per mile driven and are more likely to be fatally injured if involved in a crash than are younger drivers. ${ }^{1}$ Concern for the safety of the older driver has led many investigators to search for better ways to identify risk factors for crash involvement. Clearly, driving is an intensely visual task. As most aspects of visual function decline past age 50 years, ${ }^{2}$ it has long been thought that visual impairment should be a good indicator of crash risk. However, most studies have shown a weak association, at best, between visual impairment and driving, in the general driving population. These studies have been extensively reviewed by Owsley and McGwin ${ }^{3}$ and Charman, ${ }^{4}$ among others

Briefly, people with poor acuity are more likely to report difficulty driving or to restrict driving in demanding situations, ${ }^{5}$ but static visual acuity is a poor predictor of crash involvement. ${ }^{5,6}$ The relationship is somewhat stronger for acuity measured dynamically ${ }^{5-7}$ or at low luminance. ${ }^{8}$ Simulated visual acuity impairment below 20/40 decreases driving performance, ${ }^{9}$ but older people with acuities in the range of 20/40 to $20 / 50$ are no more likely to be involved in a crash than are people with acuity better than $20 / 40 .{ }^{10}$

Reduced contrast sensitivity is associated with poor driving performance, ${ }^{11}$ self-reported driving difficulty, ${ }^{12}$ self-restriction, ${ }^{5}$ and prior crash involvement. ${ }^{13,14}$ Poor contrast sensitivity is also a predictor of future crashes, but the association is not significant after adjustment for miles driven and other predictors of crash involvement. ${ }^{7}$

Many older drivers complain of glare, especially while driving at night; however, disability glare tests have not been found to be associated with driving performance, crashes, or selfreported driving difficulty. Nevertheless, disability glare and glare recovery do predict self-restriction in driving behavior. ${ }^{8}$

The role of binocularity and stereopsis in driving safety remains controversial. Stereo deficiency is associated with selfreported driving difficulty, ${ }^{12}$ driving restriction, ${ }^{8}$ and possibly crash involvement, ${ }^{10,15}$ but the latter may be attributable to a mismatch in acuity between the two eyes, rather than to poor stereopsis per se. ${ }^{4}$

Several studies have been conducted to examine the link between visual field restriction and driving. Simple monocular screening tests are poor predictors of crash involvement in the general population, ${ }^{16}$ but in a study of 10,000 California drivers, ${ }^{17}$ accident rates were twice as great among those with abnormal fields in both eyes than among those with monocular abnormalities or normal visual fields. Simulated binocular (but not monocular) field restriction also impairs closed-course driving performance. ${ }^{11}$ Visual field restriction is associated with self-reported crash involvement in patients with glaucoma ${ }^{4}$ and retinitis pigmentosa ${ }^{4,18}$ and with self-reported driving restriction among older drivers in general. ${ }^{8}$ However, it has generally been found that driving performance is more closely linked to the functional or "attentional" field for older drivers. Conventional visual field tests measure the area over which a target can 
be detected when presented in isolation. The functional field describes the area over which a target can be detected and localized while simultaneously attending to a target at fixation (divided attention), sometimes in the presence of distracters elsewhere in peripheral vision (selective attention). The functional field is most often referred to as the useful field of view (UFOV) after the pioneering work of Ball et al. ${ }^{19}$ The UFOV is predictive of prior crash involvement, ${ }^{13}$ future crashes, ${ }^{7}$ and self-restriction in driving behavior. ${ }^{8}$ The UFOV has shown the strongest association with crash involvement of any visionrelated tests. Older drivers with a $40 \%$ reduction in UFOV were six times more likely to have had a crash in the previous 5 years $^{13}$ and were 2.2 times more likely to have a crash in the subsequent 3 years. $^{7}$

Previous studies of vision and motor vehicle crashes have varied in sampling methodology (population-based versus casecontrol), how crashes were ascertained (self-report versus state records), and whether the studies were retrospective or prospective. The SEE study, a large, population-based prospective study provided the most appropriate methodology for our primary purpose: to determine the visual risk factors for motor vehicle crashes. Other investigators have found that self-report is poorly correlated with state records of motor vehicle crashes. ${ }^{20}$ Therefore, we elected to use objectively ascertained crash data from state motor vehicle records.

\section{Methods}

\section{Subjects}

This study was part of the Salisbury Eye Evaluation (SEE) Study (West S, et al. IOVS 1995;36:ARVO Abstract 1927), a longitudinal, populationbased study of eye disease and visual impairment and their impact on disability in older persons. Salisbury is a semirural area, with no buses and limited access to transportation other than by private car. The study sample consisted of 1801 current drivers with valid Maryland driver's licenses who were members of the original SEE study cohort (2520 participants). The SEE sample was drawn from the Health Care Financing Administration (HCFA) Medicare eligibility lists of individuals living in the Salisbury, Maryland, metropolitan area, aged 65 to 84 years. The sample included $100 \%$ of the identified African American residents and an age-stratified random sample of $58 \%$ of identified white residents. No other ethnic groups were represented. A detailed description of the sampling procedure has been published. ${ }^{21}$ To be eligible for the study, the participant had to score higher than 17 on the Mini-Mental State Examination $\left(\mathrm{MMSE}^{22}\right.$ ) and be able to travel to the SEE clinic for examination. Informed consent was obtained (in accordance with the Declaration of Helsinki) using forms approved by the institutional human experimentation committee, and a 2-hour in-home interview was administered, followed by a 4 - to 5 -hour clinic examination. All testing related to our report was conducted between September 16, 1993, and September 26, 1995.

The overall participation rate for the original SEE study was $65 \%$. Approximately half of the eligible subjects who refused to participate in the study agreed to answer a brief subset of the home questionnaire. Those refusing were somewhat older, more likely to be female, less likely to have completed high school, and more likely to be living alone than those who participated. There were no significant differences between participants and refusals by race or self-assessed vision status. Details on differences between refusals and participants have been published elsewhere. $^{23}$

SEE study participants were invited to return for follow-up examinations at 2, 6, and 8 years after the baseline examination. Records of participants who did not return for follow-up were examined to determine whether they had died or been admitted to a nursing home before the end of the crash reporting period (December 31, 1997).

\section{Baseline Variables}

Demographic variables, including age at the time of the clinic examination, gender, race, years of education, and living arrangements were compiled from the home interview. Cognitive status was assessed with the MMSE, ${ }^{22}$ and the number of comorbidities was elicited with a structured medical history questionnaire, both during the home interview. Comorbidities included arthritis, broken hip, cardiovascular disease, hypertension, diabetes, emphysema, asthma, Parkinson's disease, cancer, and stroke. Depression was assessed with the depression scale of the General Health Questionnaire ${ }^{24}$ as part of the clinic examination.

\section{Vision Tests}

A detailed description of the vision tests has been published. ${ }^{25}$ All vision tests were administered by trained technicians using strict forced-choice testing procedures.

Visual Acuity. Distance acuity was tested with the Lighthouse version of the Early Treatment Diabetic Retinopathy Study (ETDRS) charts within a light box (The Lighthouse, Inc., New York, NY). ${ }^{26}$ Acuity was measured monocularly and binocularly, with habitual refractive correction at normal $\left(130 \mathrm{~cd} / \mathrm{m}^{2}\right)$ and low $\left(5.2 \mathrm{~cd} / \mathrm{m}^{2}\right)$ luminance. Visual acuity was scored as the total number of letters read correctly and was converted to $\log$ MAR $\left(\log _{10}\right.$ minimum angle resolvable) according to the method recommended by Bailey et al. ${ }^{27}$

Contrast Sensitivity. Contrast sensitivity was measured with the Pelli-Robson letter-sensitivity test. ${ }^{28}$ The test was administered monocularly at $1 \mathrm{~m}$ under controlled room illumination $\left(\sim 100 \mathrm{~cd} / \mathrm{m}^{2}\right)$. Contrast sensitivity was scored letter by letter ${ }^{29}$ and for reporting purposes was converted to $\log$ contrast sensitivity $\left(\log _{10} 1 /\right.$ contrast of letters at the threshold of visibility) in the better-seeing eye.

Glare Sensitivity. Glare sensitivity was measured with the PelliRobson chart viewed monocularly through the Brightness Acuity Tester (BAT; Mentor, Norwell, MA). Contrast sensitivity was measured first without and then with the glare light turned on (medium setting, $350 \mathrm{~cd} / \mathrm{m}^{2}$ ), and glare sensitivity was defined as the number of letters correctly identified without glare minus the number of letters identified with glare. Glare sensitivity in the better-seeing eye was used for all analyses.

Stereoacuity. Stereoacuity was tested with the Randot Circles test (Stereo Optical, Chicago, IL). The test consists of a series of 10 panels that form a graded disparity series from a maximum of 457 to 17 arc sec when viewed at a distance of $36 \mathrm{~cm}$. The panels were tested in order, beginning with the largest disparity and continuing until there was an incorrect response. The participant's score was the disparity (in seconds of arc visual angle) of the panel before the first incorrect response. Participants were classified as stereodeficient if they could not identify the disparate circle in any of the panels (stereoacuity worse than 457 arc sec).

Visual Fields. Visual fields were tested separately in each eye by using the 81-point, single-intensity screening test strategy on the Humphrey Field Analyzer (Carl Zeiss Meditec, Inc., Dublin, CA). This strategy tests points over a $60^{\circ}$ (radius) field with a single target intensity of $24 \mathrm{~dB}$. If the fixation losses, false negatives, or false positives exceeded $20 \%$, the test was stopped, and the participant was reinstructed before undertaking a new test. Field tests were scored two ways. First, the number of points missed was simply counted. Second, visual fields for the two eyes were combined according the method described by Turano et al. ${ }^{30}$ This method derives a binocular visual field as a composite of the more sensitive of the corresponding visual field locations for each eye. A similar method using threshold monocular fields has been validated by Nelson-Quigg et al. ${ }^{31}$ The binocular field is composed of 96 points that were further subdivided into the central region $\left(\leq 20^{\circ}\right.$ radius; 56 points) and the upper and lower peripheral regions (18 and 22 points, respectively). 


\section{Test of Attention}

Visual attention was evaluated with an early prototype of the UFOV test $^{13}$ (Visual Awareness, Chicago, IL). This test measures a person's ability to recognize one object while determining the location of another. The test is divided into three parts, all administered on a video display connected to a laboratory computer. The first subtest measures processing speed. The participant must discriminate between a briefly presented cartoon drawing of a car or truck at the center of the display. The test uses a proprietary algorithm to determine the minimum exposure duration at which the drawing can be consistently recognized. The second subtest measures divided attention. The participant must discriminate the car or truck while locating a second car or truck presented away from the center of the display. Accuracy of localization responses is used to determine the area of the visual field over which attention can be divided. The third subtest is the same as the second, except that the peripheral target is presented among a field of distracters, simple triangles similar in size to the car and truck. Accuracy of localization in the presence of distracters is used to measure selective attention. Each of the three tests is scored on a 0- to 30-point scale, and the three scores are added together to give an overall index of the UFOV. The currently available UFOV test differs from the one used in this study, in that it does not directly measure the field of view restriction

Because of time constraints, the UFOV test was administered to half of the participants, selected randomly at the time of enrollment. There were no statistically significant differences between those who took the UFOV test and those who did not, in age, race, gender, education level, or visual acuity (all $P>0.5$ ).

\section{Driving Assessment}

The participants' demographic, health, and driving status were assessed during the home interview. The number of miles driven during the year before the interview was ascertained, and participants who reported driving fewer than 500 miles during the prior year $(n=366)$ were excluded from the analyses, as most were not driving. A follow-up home interview was conducted 2 years later to determine changes in driving status. Crash data were obtained from the Maryland Automated Accident Reporting System (MAARS) for the years 1991 to 1997 for all participants who were licensed to drive in Maryland. The MAARS data were matched to those of the SEE participants by driver's license number. Although the MAARS records contain information about the driver, vehicle, and circumstances of the crash, the only data used for this study were the crash dates. No attempt was made to determine whether the SEE participant driver was at fault.

\section{Data Analysis}

Survival analyses were used to determine the relative risk of being involved in a crash as a function of demographic and health status variables, miles driven, vision, and visual attention at baseline. A crash qualified for inclusion in the analyses if it occurred after the baseline examination date. Cox proportional hazards models were used to analyze times from baseline examination to first crash. Data were censored if the participant stopped driving, died, or moved to a nursing home before the end of follow-up or reached the end of follow-up without being involved in a crash. Separate models were fit with and without adjustment for four aspects of driving behavior. The first was miles driven in the year before the baseline examination, which was treated as a categorical variable by quintiles $(\leq 2,000$, $2,001-5,000,5,001-8,000,8,001-12,000,>12,000$ miles). The second was a reduction to fewer than 3000 miles per year at follow-up among drivers who were driving 3000 or more miles per year at baseline. The third was the cessation of night driving during follow-up among those who were driving at night at baseline, and fourth was the cessation of driving in unfamiliar areas at follow-up. Our previous work has shown that older drivers with worse vision were more likely to reduce mileage and to avoid driving in high-risk situations. ${ }^{32}$ For the final models, $\log$-log plots, residual plots, and a global test were used to check the proportional hazards assumption. All analyses were performed with commercial software (SAS/JMP, ver. 5.1; SAS, Cary, NC).

\section{Results}

Of the 2520 participants in the original SEE Study cohort, 1801 were eligible drivers for this analysis (Fig. 1). The remaining 719 were not eligible, because they never drove $(n=187)$, did not have a current Maryland driver's license $(n=166)$, or did not drive at least 500 miles in the year before the baseline interview ( $n=366$ ). The length of follow-up (time to first crash or the end of the surveillance period) ranged from 14 to 1567 days (median, 1087; interquartile range $[\mathrm{IQR}]=933-$ 1323).

Table 1 compares baseline characteristics of eligible drivers and nondrivers. Older participants were less likely to drive $(P<0.0001)$. Logistic regression analyses adjusted for age also indicated that participants who were female, were African American, had fewer years of education, had a lower MMSE score, or reported more symptoms of depression or comorbidities were less likely to drive (all $P<0.0001$ except comorbidities $P=0.013$ ). Participants with worse vision according to any of our measures except glare were also less likely to drive (all $P<0.0001$ ). In fact, the only characteristics that failed to differentiate drivers and nondrivers were whether they lived alone and disability glare.

The MAARS records returned 290 crashes between 1991 and 1997 for SEE study participants. Thirty participants were involved in two crashes and four were involved in three. There were 120 eligible crashes (i.e., first crashes that occurred after the baseline interview). Of those who did not crash, 75 stopped driving, 124 died, and 5 were admitted to a nursing home before the end of follow-up (December 31, 1997). Date of death was confirmed by coroner's records or newspaper obituary. When that information was not available $(n=5)$, date of death was imputed by adding the sex-, age group-, and race-specific median elapsed time to death to the date entering the study. The nursing home admission date was not available, and so the date used was intermediate between the date of last follow-up and the next scheduled follow-up.

Table 2 shows the hazard ratio (HR) for crash risk by baseline characteristic. Age at baseline was a significant predictor of crash risk (hazard ratio $[\mathrm{HR}]=1.20$ per 5 years of age; 95\% CI $=1.00-1.44, P<0.05$ ). After adjustment for age, the only significant characteristics were race, with the HR for African Americans twice that for white participants $(\mathrm{HR}=$ $2.05 ; 95 \% \mathrm{CI}=1.37-3.02, P=0.0007$ ) and mental status, with a hazard ratio of 0.91 for a 1-point increase in MMSE score $(95 \%$ $\mathrm{CI}=0.85-0.98, P=0.02)$. There was a trend for women to be less prone to crashes than men $(\mathrm{HR}=0.72 ; 95 \% \mathrm{CI}=0.50$ 1.03, $P=0.08$ ). Living alone, education level, number of comorbidities, and depression were not related to crash risk $(P>0.1)$, after adjustment for age. The hazard ratios were similar when adjusted for miles driven (shown in italics in Table 2).

Nearly $13 \%$ of the participants $(n=227)$ failed the stereoacuity screening test at 457 arc sec. These participants were categorized as stereodeficient. Given the large number of failures and the coarse quantization of this test, stereoacuity was treated as a binary variable for the remaining analyses. Key analyses were confirmed with stereoacuity treated as a continuous variable. Figure 2 shows unadjusted crash rates for each quintile of the remaining vision variables and UFOV. It should be emphasized that these raw, unadjusted crash rates do not establish the crash risk associated with each of the variables (as they do not account for potential confounding factors) but are 


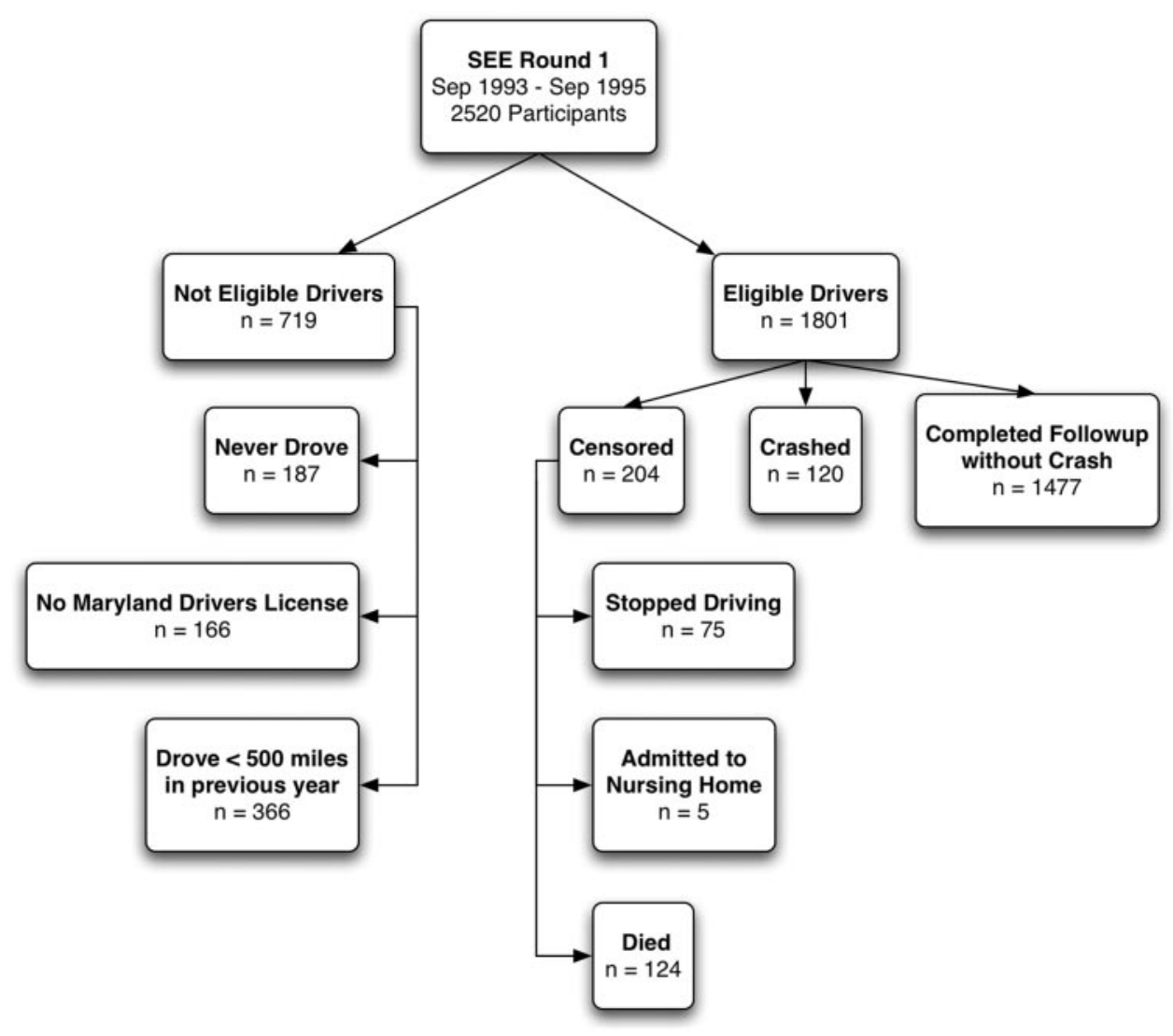

FIGURE 1. Characterization of the sample of eligible drivers.

useful for assessing the nature of the possible relationship between the variable and crash risk (is it linear or nonlinear?), to guide further modeling.

Several of the vision measures appear to be nonlinearly related to crash rate in Figure 2, particularly glare sensitivity and visual fields, and possibly contrast sensitivity and UFOV. These nonlinearities suggest that crash rate declined with small amounts of vision loss and then increased with more substantial loss. Therefore, additional terms were included to allow the estimate of risk to vary above and below an inflection point for these variables. The inflection point was used to develop spline or piecewise linear regression models. ${ }^{33}$ For contrast sensitivity, the inflection point was set at $1.7 \log \mathrm{CS}$, for glare sensitivity at 3 letters and for visual fields at 20 points missed. Analyses were repeated with adjustments of the inflection points and the results were essentially the same. The addition of an inflection point for contrast sensitivity did not significantly improve the fit of the model, and so it was dropped from subsequent analyses.

Table 3 presents the crash risk for each of the vision variables modeled individually and adjusted for demographics and health status variables (age, race, gender, MMSE, education, living alone, depression and comorbidity score). HRs are computed for a 15-letter loss of visual acuity (0.3 logMAR or a doubling of the visual angle), a six-letter worsening of contrast or glare sensitivity ( $0.3 \log C S$ or a doubling of threshold contrast), and a loss of 15 points in visual fields. These values were derived from previous studies showing that these levels of vision loss are associated with a significant increase in selfreported disability or a measurable decline in performance. ${ }^{34}$

Acuity at normal and low luminance, contrast sensitivity, and stereoacuity were not significant predictors of crash risk $(P>0.1)$. Glare sensitivity and binocular visual fields were associated with crash risk. For both measures, vision loss for those with moderate or better levels of vision $(<3$ letters for glare sensitivity and $<20$ points missed for binocular visual fields) was associated with a reduction in crash risk $(\mathrm{HR}=0.46$ for a 6-letter worsening of glare sensitivity, $P=0.02$; $\mathrm{HR}=$ 0.60 for a loss of 15 points in visual fields, $P=0.07$ ), whereas a vision loss for those with poorer levels of vision than these was associated with increased crash risk $(\mathrm{HR}=2.18$ for glare sensitivity for a 6-letter worsening of glare sensitivity, $P=0.04$; $\mathrm{HR}=1.29$ for a loss of 15 points of visual fields, $P=0.03$ ).

The visual field data were further analyzed to determine which part of the field was most critical for crash risk. The binocular visual field was divided into central $\left(\leq 20^{\circ}\right)$, upper, and lower regions (see the Methods section). Plots of unadjusted crash rates versus visual field score were examined for nonlinearity. The data for the lower peripheral field scores showed a strong nonlinearity with an inflection point near 10 points missed. Therefore an additional term was added to the proportional hazards model to allow the estimate of risk to vary above and below the inflection point. Central and upper peripheral fields were not associated with crash risk $(P>0.5)$. However, there was a significant reduction in crash risk with lower peripheral field loss $<10$ points $(\mathrm{HR}=0.44 ; P=0.03$ ) and a significant increase in risk with lower field loss $\geq 10$ points $(\mathrm{HR}=1.96 ; P=0.01)$.

UFOV data were available for 857 of the eligible drivers. There was some evidence of a nonlinear relationship between crash rate and UFOV, with an inflection at 30-point overall UFOV loss (Fig. 2). However, the addition of an inflection point for UFOV did not significantly improve the fit of the model, and so it was dropped from subsequent analyses. HRs were computed for a UFOV loss of 40 points, as this has been shown to be predictive of future crash involvement. ${ }^{7}$ Results are given in Table 3, adjusted for demographic and health status variables. UFOV score was associated with crash risk $(\mathrm{HR}=2.12, P=$ 
TABLE 1. Baseline Characteristics of Drivers and Nondrivers

\begin{tabular}{|c|c|c|c|}
\hline & $\begin{array}{c}\text { Drivers } \\
(n=1801)\end{array}$ & $\begin{array}{c}\text { Nondrivers } \\
(n=719)\end{array}$ & \\
\hline & $\%$ & $\%$ & Age Adjusted $P$ \\
\hline \multicolumn{4}{|l|}{ Age } \\
\hline $65-69$ & 34.2 & 22.9 & \multirow[t]{4}{*}{$<0.0001$} \\
\hline $70-74$ & 34.4 & 29.9 & \\
\hline $77-79$ & 20.7 & 25.2 & \\
\hline $80-85$ & 10.7 & 22.0 & \\
\hline \multicolumn{4}{|l|}{ Gender } \\
\hline Men & 49.8 & 23.0 & \multirow[t]{2}{*}{$<0.0001$} \\
\hline Women & 50.3 & 77.0 & \\
\hline \multicolumn{4}{|l|}{ Race } \\
\hline White & 80.8 & 55.5 & \multirow[t]{2}{*}{$<0.0001$} \\
\hline African American & 19.2 & 44.5 & \\
\hline \multicolumn{4}{|l|}{ Education } \\
\hline$<9$ years & 17.6 & 35.7 & \multirow[t]{3}{*}{$<0.0001$} \\
\hline $9-12$ years & 49.7 & 47.7 & \\
\hline$>12$ years & 32.7 & 16.6 & \\
\hline \multicolumn{4}{|l|}{ Live Alone } \\
\hline Yes & 42.3 & 45.4 & \multirow[t]{2}{*}{0.99} \\
\hline No & 57.8 & 54.6 & \\
\hline \multicolumn{4}{|l|}{ MMSE score } \\
\hline $18-23$ & 3.6 & 16.8 & \multirow[t]{2}{*}{$<0.0001$} \\
\hline $24-30$ & 96.4 & 83.8 & \\
\hline \multicolumn{4}{|l|}{ Depression } \\
\hline None & 93.1 & 84.1 & \multirow[t]{2}{*}{$<0.0001$} \\
\hline Some & 6.9 & 15.9 & \\
\hline \multicolumn{4}{|l|}{ No. of comorbidities } \\
\hline 0 & 9.6 & 9.3 & \multirow[t]{3}{*}{0.013} \\
\hline 1 & 21.8 & 19.1 & \\
\hline $2+$ & 68.7 & 71.7 & \\
\hline \multicolumn{4}{|c|}{ Presenting binocular acuity (logMAR) } \\
\hline Better than $20 / 25(<0.1)$ & 81.9 & 60.3 & \multirow[t]{3}{*}{$<0.0001$} \\
\hline $20 / 25-20 / 40(0.1-0.3)$ & 14.8 & 23.7 & \\
\hline Worse than $20 / 40(>0.3)$ & 3.2 & 15.9 & \\
\hline \multicolumn{4}{|l|}{ Log contrast sensitivity (letters) } \\
\hline$>1.65(>36)$ & 50.9 & 29.1 & \multirow[t]{3}{*}{$<0.0001$} \\
\hline $1.35-1.65(30-36)$ & 46.0 & 56.4 & \\
\hline$<1.35(<30)$ & 3.1 & 14.5 & \\
\hline \multicolumn{4}{|l|}{ Glare disability (letters) } \\
\hline$<1$ & 33.8 & 33.9 & 0.86 \\
\hline $1-3$ & 45.7 & 41.4 & \\
\hline$>3$ & 20.5 & 24.7 & \\
\hline Stereoacuity test & & & \\
\hline Passed & 82.1 & 68.9 & $<0.0001$ \\
\hline Failed & 17.9 & 31.1 & \\
\hline Visual field points missed & & & \\
\hline$<10$ & 14.8 & 8.7 & $<0.0001$ \\
\hline $10-20$ & 37.0 & 19.9 & \\
\hline$>20$ & 48.2 & 71.4 & \\
\hline Useful Field of View overall s & & & \\
\hline$<30$ & 9.9 & 5.2 & $<0.0001$ \\
\hline $30-60$ & 57.8 & 34.3 & \\
\hline$>60$ & 32.3 & 60.5 & \\
\hline
\end{tabular}

0.002). The pattern of results for the other vision variables is quite similar for this subset of participants compared to the results for the entire sample.

The UFOV score is a composite of three separately measured components that are described as processing speed, divided attention, and selective attention (see the Methods section). When the three subtests were analyzed separately, the strongest association was with divided attention (divided attention: $\mathrm{HR}=1.47, P=0.001$; processing speed: $\mathrm{HR}=1.27$, $P=0.04$; selective attention: $\mathrm{HR}=1.45, P=0.22$ ). Hazard ratios were computed for a 10-point loss, from a maximum of 30 points possible. Note, however, that there was a significant floor effect for processing speed, with 662 (77\%) participants scoring 0 (no loss), and a significant ceiling effect for selective attention, with 493 (58\%) participants scoring 30 (maximum loss). The analyses were repeated with an adjustment for miles driven. The results, shown in the right columns of Table 3, are quite similar to those without the mileage adjustment.

For glare sensitivity and visual fields we observed that a small vision loss was associated with a reduced risk of crashes, whereas a greater vision loss was associated with increased risk. To explore this surprising result further, we investigated the relationship between vision loss and changes in driving behavior that may be related to reduced risk of crash involvement. Participants were categorized as having driven fewer miles or given up driving at night or in unfamiliar places based 
TABLE 2. Analysis of Baseline Characteristics

\begin{tabular}{|c|c|c|c|c|}
\hline Variable & Interval for Hazard Ratio & Hazard Ratio & $95 \% \mathrm{CI}$ & $\boldsymbol{P}$ \\
\hline \multirow[t]{2}{*}{ Age } & 5 years & 1.20 & $1.00-1.44$ & 0.05 \\
\hline & & 1.22 & $1.02-1.47$ & 0.03 \\
\hline \multirow[t]{2}{*}{$\operatorname{Sex}^{*}$} & Female & 0.72 & $0.50-1.03$ & 0.08 \\
\hline & & 0.75 & $0.49-1.13$ & 0.08 \\
\hline \multirow[t]{2}{*}{ Race* } & African American & 2.05 & $1.37-3.02$ & 0.0007 \\
\hline & & 2.11 & $1.41-3.11$ & 0.0004 \\
\hline \multirow[t]{2}{*}{ Live Alone* } & Yes & 0.75 & $0.52-1.07$ & 0.11 \\
\hline & & 0.73 & $0.51-1.05$ & 0.09 \\
\hline \multirow[t]{2}{*}{ Education* } & 6 years & 1.02 & $0.74-1.42$ & 0.91 \\
\hline & & 0.99 & $0.72-1.39$ & 0.99 \\
\hline \multirow{2}{*}{ Mental Status* } & 1 point & 0.91 & $0.85-0.98$ & 0.02 \\
\hline & & 0.91 & $0.85-0.98$ & 0.02 \\
\hline \multirow[t]{2}{*}{ Comorbidities* } & 1 & 1.05 & $0.93-1.67$ & 0.45 \\
\hline & & 1.04 & $0.93-1.16$ & 0.47 \\
\hline \multirow[t]{2}{*}{ Depression* } & Some & 0.97 & $0.71-1.41$ & 0.84 \\
\hline & & 0.95 & $0.70-1.39$ & 0.79 \\
\hline
\end{tabular}

Italic data are adjusted for age and miles driven.

* Adjusted for age.

on responses to the driving habits portion of the home interview at baseline and follow-up.

Sixteen percent of participants decreased their mileage from 3000 or more miles at baseline to fewer than 3000 miles at follow-up. Thirteen percent stopped driving at night, and $33 \%$ stopped driving in unfamiliar areas. (These percentages differ slightly from those reported previously in Freeman et al. ${ }^{32}$ because the present study included only drivers with current Maryland driver's licenses.) However, adding these modification factors to the proportional hazards models did not change the results (data not shown).

\section{Discussion}

From the original cohort of 2520 SEE participants, we identified 1801 current drivers, of whom 120 were involved in a crash during the time between the baseline examination and the end of surveillance (December, 1997). As expected, drivers were significantly younger, healthier, and had better vision than did nondrivers (Table 1). However, it is interesting to note that 208 current drivers (11.5\%) had presenting monocular visual acuities worse than 20/40 in at least one eye and should not have qualified for an unrestricted driver's license in Maryland.

Distance acuity at normal and low luminance, contrast sensitivity, and stereoacuity were not predictive of crash involvement in our cohort. Glare sensitivity, visual fields, and UFOV were significant predictors. Several previous studies have found that distance acuity and contrast sensitivity are at least weakly associated with crash involvement (see the introduction). We did not find such an association. However, SEE study participants with poor acuity or contrast sensitivity were much less likely to drive. For example, SEE participants with a visual acuity worse than $20 / 40(0.3 \log$ MAR $)$ or a contrast sensitivity worse than $1.35 \log \mathrm{CS}$, were twice as likely not to drive as were participants with good vision $(\mathrm{OR}=2.17,95 \% \mathrm{CI}=$ 1.85-2.56 for acuity; $\mathrm{OR}=2.08,95 \% \mathrm{CI}=1.75-2.49$ for contrast sensitivity). Other analyses of the SEE study cohort have indicated that poor acuity and contrast sensitivity were associated with driving cessation during the eight years after the baseline examination. ${ }^{35}$ These findings suggest that either state licensing laws or self-regulation on the part of older drivers is effective in reducing the risk of crash involvement due to some forms of visual impairment.
The role of glare in visual disability remains controversial. We have previously reported that glare sensitivity is associated with self-reported difficulty with daily activities, including driving, ${ }^{12,34}$ and now with crash involvement (for $\geq 3$ letters lost in glare). However, results of tests of glare sensitivity were not found to be related to daily activities ${ }^{36}$ or crash involvement ${ }^{14}$ in patients with cataracts, for whom glare is a frequently reported symptom. Glare sensitivity has been linked to driving self-restriction, ${ }^{8}$ although glare sensitivity was the only vision measure that did not differentiate drivers from nondrivers in the present study. Surprisingly, we found that increased glare sensitivity for those with good vision significantly reduces the risk of crash involvement. This paradoxical relationship could be due to greater modification of driving behavior in that group. However, adjusting the proportional hazards model for these modifications did not change the paradoxical relationship.

Visual fields are known to play an important role in mobility, and we have shown that field loss is associated with a decline in mobility performance ${ }^{30}$ and driving cessation ${ }^{35}$ in the SEE cohort. In those studies, in which we used the same measure of binocular visual fields, field loss in the central and lower peripheral regions was associated with mobility performance and driving cessation, whereas field loss in the upper peripheral region was not. In the present study, the field losses in the lower peripheral region were the most important for predicting future crash involvement. Furthermore, crash involvement is only predicted by binocular field loss, not monocular loss (data not shown). This is consistent with the work of Johnson and Keltner, ${ }^{17}$ Wood and Troutbeck, ${ }^{11}$ and Wood. ${ }^{37}$ Binocular fields have also been shown to relate more closely than monocular fields to self-reported difficulty with daily tasks. ${ }^{38}$ However, as for glare sensitivity, we found that the relationship between visual field loss and crashes was complex). In those with reasonably good visual fields $(<20$ points missed), vision loss was, paradoxically, associated with a reduction in crash risk, whereas in those with poorer visual fields, vision loss was associated with increased crash risk. As previously reported, ${ }^{32}$ those with central and lower peripheral field loss were more likely to reduce the number of miles driven and to stop night driving. Self-regulation also appears to play a role in reducing crash risk among patients with glaucoma,${ }^{39}$ juvenile macular dystrophies, ${ }^{40}$ and age-related macular degeneration ${ }^{41}$ who have a lower crash rate than agematched control subjects, despite worse vision. However, 

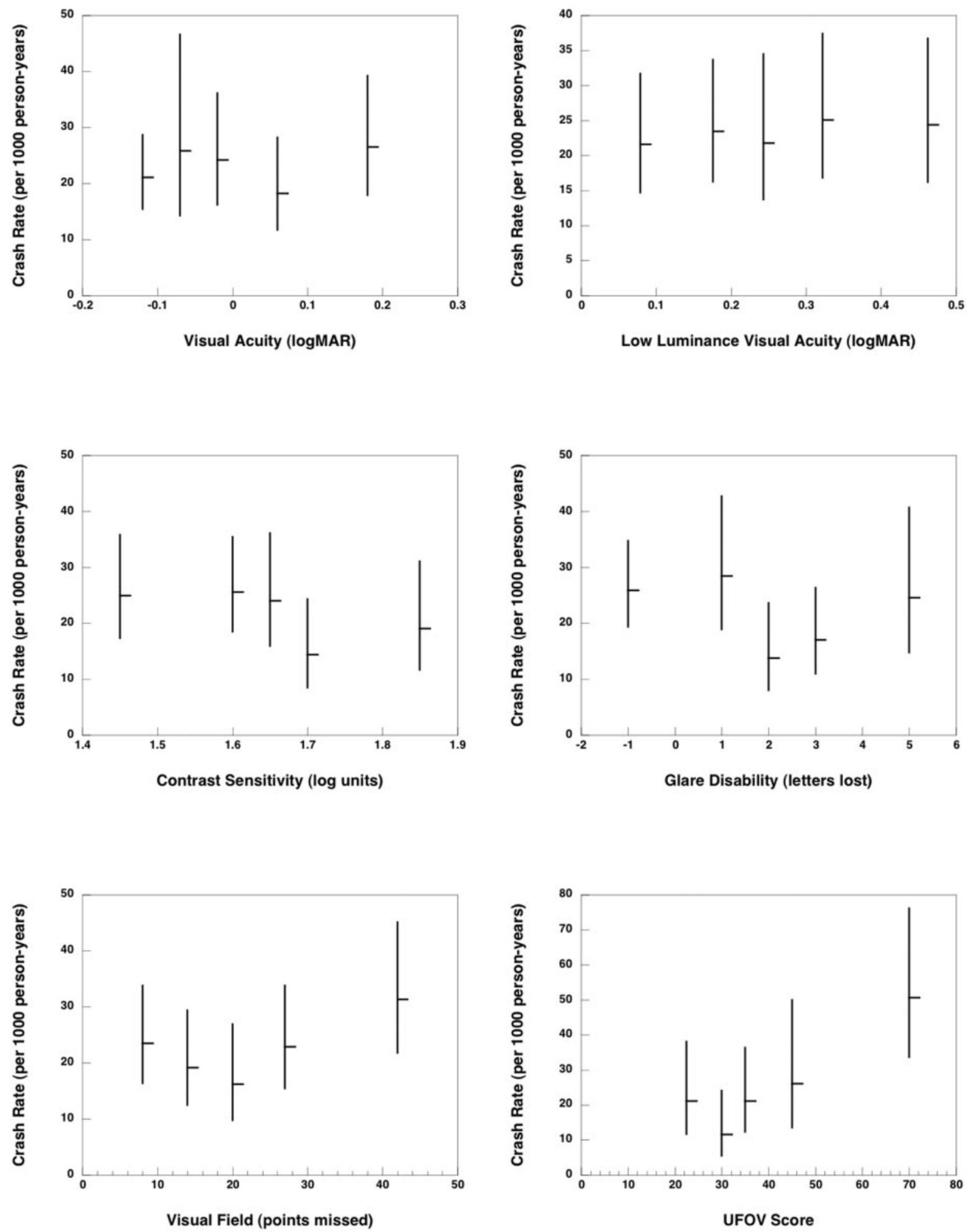

Figure 2. Plots showing unadjusted crash rates for each of the vision tests and the UFOV test, divided into quintiles.

when the proportional hazards models were adjusted for these modifications, the paradoxical relationship remained.

As has been reported by others, we found that UFOV is a strong predictor of crash involvement. Participants with a 40-point loss in UFOV were 2.12 times more likely to crash than those with no loss of UFOV. Approximately $41 \%$ of the participants in this cohort had a UFOV loss $\geq 40$ points. These results are similar to those reported by Owsley et al. $^{7}$ in a prospective cohort study of older drivers. Of the three component tests in the UFOV battery, the divided-attention test (localization of a peripheral target while detecting a central target) was the best predictor of crash involvement. This test is intermediate in difficulty between the easier processing-speed test (detection of central target only) and the more difficult selective-attention test (localization of peripheral target with distracters). We expect that the divided attention task was 


\begin{tabular}{|c|c|c|c|c|c|c|}
\hline \multirow[b]{2}{*}{ Variable } & \multirow[b]{2}{*}{$n$} & \multirow[b]{2}{*}{ Interval for Hazard Ratio } & \multicolumn{2}{|c|}{ No Mileage Adjustment } & \multicolumn{2}{|c|}{ Adjusted for Miles Driven } \\
\hline & & & Hazard Ratio & $95 \% \mathrm{CI}$ & Hazard Ratio & 95\% CI \\
\hline Acuity & 1801 & -15 Letters & 1.16 & $0.77-1.68$ & 1.17 & $0.78-1.70$ \\
\hline Low luminance acuity & 1800 & -15 Letters & 1.06 & $0.75-1.46$ & 1.06 & $0.75-1.47$ \\
\hline Contrast sensitivity $<1.7$ & 1797 & -6 Letters & 0.75 & $0.49-1.21$ & 0.75 & $0.49-1.21$ \\
\hline Contrast sensitivity $\geq 1.7$ & & -6 Letters & 1.25 & $0.43-5.57$ & 1.25 & $0.44-5.65$ \\
\hline Glare sensitivity $<3$ & 1773 & 6 Letters & 0.46 & $0.26-0.89 *$ & 0.46 & $0.26-0.89^{*}$ \\
\hline Glare sensitivity $\geq 3$ & & 6 Letters & 2.18 & $1.13-16.16^{*}$ & 2.32 & $1.14-16.78^{*}$ \\
\hline Stereodeficient & 1796 & Yes & 1.44 & $0.88-2.26$ & 1.44 & $0.88-2.27$ \\
\hline Binocular visual fields $<20$ & 1771 & 15 Points & 0.60 & $0.35-1.03$ & 0.59 & $0.34-1.00$ \\
\hline Binocular visual fields $\geq 20$ & & 15 Points & 1.29 & $1.09-4.06^{*}$ & 1.31 & $1.13-4.27^{*}$ \\
\hline UFOV & 857 & $40 \%$ Loss & 2.12 & $1.32-3.39^{* * *}$ & 2.21 & $1.32-3.39^{* * *}$ \\
\hline
\end{tabular}

All models adjusted for age, race, sex, MMSE Score, education, comorbidities, living alone, and depression.

${ }^{*} P<0.05$.

$* * P<0.01$

best, because the processing-speed task was subject to a substantial floor effect whereas the selective-attention task was subject to a ceiling effect. The ceiling effect problem was also reported by Wood and Troutbeck ${ }^{11}$ in their study of simulated visual impairment in elderly drivers.

The association of visual impairment with crashes was not altered by whether or not the model was adjusted for number of miles driven. In fact, mileage was not a significant predictor of crash involvement in our cohort, whether it was treated as a continuous or categorical variable (data not shown), perhaps because we used miles driven during the year before the baseline examination, rather than miles driven during the surveillance period (which was not available to us).

Our study was limited by the relatively low number of crashes that were identified during the surveillance period. We did not determine whether the driver involved in a crash was at fault. It has generally been found that visual function is a better predictor of at-fault crashes. ${ }^{3}$ The data on driving modification were based on interviews conducted at baseline and 2 years later and only included a gross estimate of miles driven and qualitative data about night driving and driving in unfamiliar areas. Also any changes that occurred during the intervening period but before a crash would not have been recorded. Finally, Salisbury, Maryland, is a semirural area. Although it has a freeway and a small urban center, our findings may not generalize to larger cities with more dense populations.

In summary, binocular visual fields, glare sensitivity, and UFOV were significant predictors of crash involvement in our cohort of older drivers. The association with UFOV score was quite robust, whereas the association with visual fields and glare depended on the level of vision loss. Participants with very mild visual field loss or glare sensitivity showed a reduced risk of crash involvement; those with more severe deficits showed an increased risk. The reduction in crash risk with mild visual field or glare sensitivity loss is not explained by the self-reported changes in driving behavior in this population. Participants with poor acuity, poor contrast sensitivity, and visual field loss have been reported to be more likely to change their driving behavior in demanding situations, but at least for glare and visual fields, we could not confirm that such changes altered risk of crashes. Our assessment of the role of driving modification is limited to self-reported changes in driving behavior, rather than objective assessments. Nevertheless, the data suggest that current vision screening for driver's licensure, which is based primarily on visual acuity, may miss important aspects of visual impairment about which the driver is not sufficiently aware.

\section{References}

1. U.S. Department of Transportation. Improving Transportation for a Maturing Society. Washington, DC: Department of Transportation; 1997.

2. Johnson MA, Choy D. On the definition of age-related norms for visual function testing. Appl Opt. 1987;26:1449-1454.

3. Owsley C, McGwin G Jr. Vision impairment and driving. Surv Ophthalmol. 1999;43:535-550.

4. Charman WN. Vision and driving: a literature review and commentary. Ophthalmic Physiol Opt. 1997;17:371-391.

5. Keeffe JE, Jin CF, Weih LM, McCarty CA, Taylor HR. Vision impairment and older drivers: who's driving? Br J Ophthalmol. 2002;86: 1118-1121.

6. Hills B, Burg A. A Reanalysis of Californian Driver Vision Data: General Findings. Berkshire, UK: Crowthorne; 1977.

7. Owsley C, Ball K, McGwin G Jr, et al. Visual processing impairment and risk of motor vehicle crash among older adults. JAMA. 1998; 279:1083-1088.

8. West CG, Gildengorin G, Haegerstrom-Portnoy G, Lott LA, Schneck ME, Brabyn JA. Vision and driving self-restriction in older adults. J Am Geriatr Soc. 2003;51:1348-1355.

9. Wood J, Higgins K. How well does high contrast visual acuity predict driving performance? In: Gale A, ed. Vision in Vehicles VII. Amsterdam: Elsevier; 1999:33-42.

10. Gresset JA, Meyer FM. Risk of accidents among elderly car drivers with visual acuity equal to $6 / 12$ or $6 / 15$ and lack of binocular vision. Ophthalmic Physiol Opt. 1994;14:33-37.

11. Wood JM, Troutbeck R. Elderly drivers and simulated visual impairment. Optom Vis Sci. 1995;72:115-124.

12. Rubin GS, Bandeen-Roche K, Prasada-Rao P, Fried LP. Visual impairment and disability in older adults. Optom Visual Sci. 1994; $71: 750-760$.

13. Ball K, Owsley C, Sloane ME, Roenker DL, Bruni JR. Visual attention problems as a predictor of vehicle crashes in older drivers. Invest Ophthalmol Vis Sci. 1993;34:3110-3123.

14. Owsley C, Stalvey BT, Wells J, Sloane ME, McGwin G Jr. Visual risk factors for crash involvement in older drivers with cataract. Arch Ophthalmol. 2001;119:881-887.

15. Shute RH, Woodhouse JM. Visual fitness to drive after stroke or head injury. Ophthalmic Physiol Opt. 1990;10:327-332.

16. Ginsburg AP. Is the illusory triangle physical or imaginary? Nature. 1975;257:219-220.

17. Johnson CA, Keltner JL. Incidence of visual field loss in 20,000 eyes and its relationship to driving performance. Arch Ophthalmol. 1983;101:371-375.

18. Szlyk JP, Alaexander KR, Severing K, Fishman GS. Assessment of driving performance in patients with retinitis pigmentosa. Arch Ophthalmol. 1992;110:1709-1713. 
19. Ball KK, Beard BL, Roenker DL, Miller RL, Griggs DS. Age and visual search: expanding the useful field of view. J Opt Soc Am A. 1988;5:2210-2219.

20. McGwin G Jr, Owsley C, Ball K. Identifying crash involvement among older drivers: agreement between self-report and state records. Accid Anal Prev. 1998;;30:781-791.

21. West SK, Muñoz B, Rubin GS, et al. Function and visual impairment in a population-based study of older adults: SEE Project. Invest Ophthalmol Vis Sci. 1997;38:72-82.

22. Folstein MF, Folstein SE, McHugh PR. 'Mini-mental state': a practical method for grading the cognitive state of patients for the clinician. J Psychiatr Res. 1975;12:189-198.

23. Munoz B, West S, Rubin GS, Schein OD, Fried LP, Bandeen-Roche $\mathrm{K}$. Who participates in population based studies of visual impairment?-The Salisbury Eye Evaluation project experience. Ann Epidemiol. 1999;9:53-59.

24. Goldberg D. GHQ The Selection of Psychiatric Illness by Questionnaire. London: Oxford University Press; 1972.

25. Rubin GS, West SK, Munoz B, et al. A comprehensive assessment of visual impairment in a population of older Americans. The SEE Study. Salisbury Eye Evaluation Project. Invest Ophthalmol Vis Sci. 1997;38:557-568.

26. Ferris FL, Kassoff A, Bresnick GH, Bailey I. New visual acuity charts for clinical research. Am J Ophthalmol. 1982;94:91-96.

27. Bailey IL, Bullimore MA, Raasch TW, Taylor HR. Clinical grading and the effects of scaling. Invest Ophthalmol Vis Sci. 1991;32: 422- 432.

28. Pelli DG, Robson JG, Wilkins AJ. The design of a new letter chart for measuring contrast sensitivity. Clin Vis Sci. 1988;2:187-199.

29. Elliott DB, Bullimore MA, Bailey IL. Improving the reliability of the Pelli-Robson contrast sensitivity test. Clin Vision Sci. 1991;6:471475.

30. Turano KA, Broman AT, Bandeen-Roche K, Munoz B, Rubin GS, West S. Association of visual field loss and mobility performance in older adults: Salisbury Eye Evaluation Study. Optom Vis Sci. 2004; 81:298-307.

31. Nelson-Quigg JM, Cello K, Johnson CA. Predicting binocular visual field sensitivity from monocular visual field results. Invest $O p h$ thalmol Vis Sci. 2000;41:2212-2221.
32. Freeman EE, Munoz B, Turano KA, West SK. Measures of visual function and their association with driving modification in older adults. Invest Ophthalmol Vis Sci. 2006;47:514-520.

33. Smith PL. Splines as a useful and convenient statistical tool. Am Stat. 1979;33:57-62.

34. Rubin GS, Bandeen-Roche $\mathrm{K}$, Huang GH, et al. The association of multiple visual impairments with self-reported visual disability: SEE project. Invest Ophthalmol Vis Sci. 2001;42:64-72.

35. Freeman EE, Munoz B, Turano KA, West SK. Measures of visual function and time to driving cessation in older adults. Optom Vis Sci. 2005;82:765-773.

36. Adamsons IA, Vitale S, Stark WJ, Rubin GS. The association of post-operative subjective visual function with acuity, glare and contrast sensitivity in patients with early cataract. Arch Ophthalmol. 1996;114:529-536.

37. Wood JM. Age and visual impairment decrease driving performance as measured on a closed-road circuit. Hum Factors. 2002; 44:482- 494 .

38. Crabb DP, Viswanathan AC. Integrated visual fields: a new approach to measuring the binocular field of view and visual disability. Graefes Arch Clin Exp Ophthalmol. 2005;243:210-216.

39. McGwin G Jr, Mays A, Joiner W, Decarlo DK, McNeal S, Owsley C. Is glaucoma associated with motor vehicle collision involvement and driving avoidance? Invest Ophthalmol Vis Sci. 2004;45:39343939.

40. Szlyk JP, Fishman GA, Severing K, Alexander KR, Viana M. Evaluation of driving performance in patients with juvenile macular dystrophies. Arch Ophthalmol. 1993;111:207-212.

41. Szlyk JP, Pizzimenti CE, Fishman GA, et al. A comparison of driving in older subjects with and without age-related macular degeneration. Arch Ophthalmol. 1995;113:1033-1040.

\section{APPENDIX}

\section{SEE Project Team}

Christine Alston, David Alston, Deborah Donoway, Sherice Harrison, Millie Hernandez, Jennifer Istre-Walker, Michelle Johnson, Shelley Jones, Carolyn Porter Long, Matthew Lynch, Joshua Macintosh, Jo Ellen Mitchell, Jacquelyn Townsend, and Leslie Wilson. 